\title{
Psychological Well-Being: Using Self-determination Theory to Examine the Reciprocal Benefits of Mentoring and Teaching Others
}

\author{
Benjamin Dantzer
}

\begin{abstract}
This study explores the reciprocal benefits that high-school peer mentors experience while participating in a cross-age peer mentoring program. Mentors were trained to support the basic psychological needs (autonomy, competence, belonging) of their mentees while teaching them to play music. A pre-post mentoring self-report questionnaire was used to assess the amount of reciprocal basic psychological need satisfaction that mentors experienced. Findings indicated that mentors experienced reciprocal satisfaction for all three basic psychological needs from Time-1 (4-weeks of mentoring) to Time-2 (8-weeks of mentoring). The need for competence was the only need that demonstrated a statistically significant increase from Time-1 to Time-2. Implications for both theory and practice in classrooms is discussed.
\end{abstract}

Index Terms-Self-determination theory, cross-age peer mentoring, basic psychological needs.

\section{INTRODUCTION}

Cross-age peer mentoring is a strengths-based intervention designed to increase the relationship and leadership skills of mentors while simultaneously promoting the self-esteem, academic engagement, and sense of belonging amongst mentees [1]. Programs are designed to have two students meeting at least once a week, for a minimum of ten meetings, where they engage in conversation, play, and structured activities if provided [2]. The main difference between cross-age peer mentoring programs and other traditional mentoring programs is that, typically, mentors are high-school students, rather than adults, who are at least two years older than their mentee [3].

Within the cross-age peer mentoring literature to date, only a few theoretical perspectives exist to help explain both how and why programs promote positive outcomes in participating youth [4]. Within the theoretical frameworks that have been developed, three are commonly cited and acknowledged in the literature.

The first theory argues that mentoring impacts participating children and youth through three complementary processes: (1) improving their social relationships and psychological well-being; (2) enhancing their cognitive skills through conversation and dyadic interaction; and (3) promoting positive identity development through serving as role models (mentors) and interacting with

Manuscript received July 8, 2016; revised October 21, 2016. This research was supported by the Social Sciences and Humanities Research Council (SHHRC) under grant \#6566.

Benjamin Dantzer is with the University of British Columbia, Vancouver, Canada (e-mail: dantzerben@gmail.com). older peers (mentees) [5].

The second dominant theoretical framework originates from Attachment Theory [6] and suggests that mentoring relationships have the potential to provide youth with a corrective experience. This framework, most commonly applied to adult-with-youth programs, suggests that mentors can help mentees reorganize their internal working models of relationships through positive relationships [7]. In this model, the role of the mentor is to provide their mentee with a sense of security whereupon they can explore their environment in order to grow and develop [7].

The third theoretical framework argues that by participating in mentoring programs, mentors and mentees gain a sense of connectedness to themselves, others, and society, and thus experience positive outcomes [8]. Connectedness refers to one's interest towards and engagement with significant others and institutions, including parents (and/or other significant adults), peers, and schools [8]. With the acknowledgment that these dominant theoretical perspectives have generated useful information pertaining to mentoring and the outcomes it produces, some researchers have respectively recommended that future research examine the cross-age peer mentoring process under the lens of alternative theoretical frameworks [9]. In response to this, scholars have begun to explore the potential of a new theoretical framework, rooted in Self-Determination Theory (SDT) [10].

\section{SELF-DETERMINATION THEORY}

SDT represents an empirically based meta-theory of human motivation, personal development, and psychological well-being [10]. The theory suggests that all human beings are born with a strong sense of curiosity and willingness to learn, and that certain environmental factors can either support or discourage one's sense of well-being, self-regulation, and intrinsic motivation for learning [10]. The theory identifies three innate and basic psychological needs - autonomy, competence, and belonging.

Autonomy refers to children's sense of control over their thoughts and actions and reflects an internal locus of control [10]. Competence refers to children's confidence in their abilities to achieve desired goals and affect outcomes [10]. Lastly, belongingness is indicative of a child's feelings of acceptance and connectedness and is often indicated by the amount of value children assign to significant others and their school environment [10], [11]. 


\section{SATISFYING BASIC PSYChOlOGICAL NEEDS}

\section{A. Autonomy}

Research has identified certain environmental practices and features that influence an individual's sense of autonomy A student's sense of autonomy can be stifled when the environment consists of competition [12], controlling language [13], artificial rewards [14], threats of punishment [15], and methods of external control such as grades and excessive monitoring [16]. Alternatively, there is a growing body of research investigating how individuals can manipulate the environment of their relational partner's to promote their senses of autonomy. Autonomy promoting strategies include providing choices to relational partners [17], providing rationales for activities and decisions [18], acknowledging the other's perspective [19] and using nonevaluative and informational language [20]. Implementing these strategies is beneficial as research has repeatedly shown that when one's social partner and environment provides them with autonomy-support, their intrinsic motivation, quality and persistence of performance, and psychological well-being are all increased [21]-[24].

\section{B. Competence}

Researchers often use the terms competence and self efficacy interchangeably as they both encompass an individual's confidence in being able to accomplish the goals they set for themselves and deal with the challenges of their environments [25].

Bandura [25] highlights four primary sources of information capable of influencing one's sense of competence. These four sources include: (1) past experiences of success and failure; (2) vicarious observational learning of others; (3) self-appraisals and attributions following the completion of a task; and (4) the external feedback we receive from others after performing a task. External feedback has received the most attention in the extant literature as it is most relevant to cross-age peer mentoring and the manner in which mentors counsel their mentees [26].

It is well understood that the content and valence of feedback received from others has an influence on the recipient [25]. The influence of external feedback, however, is filtered by the receiver's interpretation of what has been said and previous experiences with similar input [27]. For instance, praising a child or student after every successful attempt, even when tasks are easy or remedial, can have a negative impact on their sense of competence if they perceive the praise to be disingenuous or unwarranted [28]. Providing appropriate feedback is thus a very intricate task requiring a certain amount of thought and specificity by the provider. Studies on the influence of appropriate feedback have illuminated two important findings. First, praise for ability can be harmful and lead to deteriorations in both well-being and motivation [28]. Second, praise for effort is a much more beneficial approach and can facilitate enduring levels of motivation, challenge seeking, and well-being [28]. However, praise needs to fit the situation. For example, don't praise effort if effort wasn't applied. Instead, provide feedback about the value of effort and, especially, effort that includes effective strategies [28]. The effects of effort-focused feedback on children and student's levels of competence will be discussed in more depth in the next section.

\section{A. Belonging}

The need to belong is a fundamental human motivation, driving us to form and maintain positive and long term relationships with others [11]. In the emerging field of neuroscience, this inherent need to belong is often discussed and linked to the idea that we are wired to connect [29]. Establishing a sense of belongingness or connectedness among participants is a primary goal of cross-age peer mentoring programs. When high-school peer mentors demonstrate fidelity to programs and meet with their mentees consistently, their younger peers report experiencing increases in their sense of belongingness and friendship [1]. Similarly, when mentors engage in cross-age peer mentoring programs and develop friendships with their mentees, they report increased amounts of connectedness to their peers and schools [1]. Studies documenting the ability of cross-age peer mentoring programs to increase participants sense of belonging are presented in the next section.

\section{SElF-DEtermination TheORY AND CROSS-AgE PEER MENTORING}

Within the existing literature on cross-age peer mentoring, only two studies were located using SDT as their theoretical framework to train mentors and evaluate outcomes [30, 31]. In the first study, researchers examined the relationship between basic psychological need satisfaction (i.e., autonomy, competence, and belonging) in mentoring relationships and subsequent mentee well-being. The authors defined and measured well-being according to three dimensions: (1) personal well-being (physical, psychological, and hope); (2) social well-being (peer relations, parental relationships and autonomy); and (3) academic well-being (perceived competence in learning) [30]. The authors hypothesized that mentored students perceiving an increase in the satisfaction of their basic psychological needs between Time-1 (after 2 months of mentoring) and Time-2 (after 8 months of mentoring) would report significantly greater outcomes in wellbeing than mentored and non-mentored peers perceiving less or unsatisfied need satisfaction. The Portuguese version of the Basic Need Satisfaction in Relationships Questionnaire (BNSIRQ) was used to measure need satisfaction among participants [30]. Mentees were randomly assigned to an experimental group $(n=157)$ that received mentoring by one of their teachers, or to a non-mentored comparison group $(n=160)$. Mentees' ranged in age from 9 to 16 years of age $(M=12.40, S D=1.81)$ with $57 \%$ being both female and in the seventh and eighth grade. No demographic information was provided for mentors.

Mentors received 16 hours of pre-mentoring training where they were informed about SDT and learned various promotion strategies related to each basic psychological need. Mentors supported their mentees' needs for autonomy by discussing and modelling self-regulatory strategies related to school attendance or behaviour and also provided information about upcoming important decisions about education and health. The need for competence was supported in this program through discussions about learning strategies and test preparation as well as providing mentees with help on their assignments. Finally, the need for 
belongingness was promoted by mentors in this program through conversations about peer and parental relationship difficulties and the provision of empathy, attention, and authenticity while doing so. Although mentors learned about the importance of balancing their efforts across all three basic needs, mentors were ultimately given the freedom to focus upon and support whichever need(s) they wished during their sessions. Mentoring took place during weekly one-on-one sessions outside of regular class time and was augmented with weekly 90-minute group sessions. During group sessions, mentor-mentee pairs collaboratively discussed issues surrounding school, social integration, and other relevant themes.

Results indicated that pre-post test variations for three of the dependent variables (hope, school environment, and perceived competence in learning) were significantly correlated with basic psychological need satisfaction among mentees [30]. Further, while comparing students who reported increased need satisfaction in both the mentored and non-mentored groups, results revealed that mentored students exhibited higher ratings for school environment, physical well-being, and perceived competence in learning compared to their non-mentored counterparts [30]. Perceptions of school environment were the only difference between the groups reaching statistical significance. Additionally, results indicated that gains on all dependent measures of wellbeing were more positive among mentees perceiving increased satisfaction of their needs compared to mentees in the opposite condition [30].

This study demonstrates the capacity for mentoring programs to increase basic psychological need satisfaction among mentees when mentors are trained in techniques known to promote each need. This study also highlights the need for mentors to adopt a more balanced approached while supporting their mentees needs. In this study, mentor training and interaction styles rooted in SDT were not significantly effective in increasing mentees' personal or social well-being, with the authors speculating that perhaps priority was given to academic gains. Research suggests that mentors should be trained to balance their relational support between the promotion of each psychological need in order to facilitate a more comprehensive intervention [10]. Another question for future research that can be drawn from this study is the implementation of peer-mentors instead of teacher-mentors. Perhaps if this study had used peer mentors, mentee gains in social well-being (autonomy, parent relationships, peer support and relationships) may have been improved. Peer mentors may have been more likely to focus on these aspects of the program compared to the academic side that teachers were more inclined to focus upon.

The second study that was located in the existing literature, implemented an experimental design to assess the impact of the Young Women Leader's Mentoring Program (YWLP), an afterschool program that pairs "at-risk" seventh grade girls with college-aged women for one year [31]. Seventh grade mentees were referred to this program by school staff who considered them to be "at-risk" academically, emotionally, and behaviorally. Mentees were then randomly assigned to an experimental group $(n=79)$ that received mentoring, or a comparison group $(n=47)$ that participated in a research project. Within the sample of mentees, $72 \%$ were minorities, with $65 \%$ of the sample received free or reduced lunch. Mentors were volunteers from a local university and although no age demographics were provided, the author's report $44 \%$ of mentors were in their second year of university.

In the YWLP, mentors were trained to follow a curriculum based on SDT during a two-semester class at their university. The class followed a service-learning format, with mentors researching topics such as issues facing adolescent girls, cultural competency, and mentoring skills in the first half of the semester and a support component in the second half, where mentors engage in supervised group mentoring sessions. The curriculum is designed to generate group discussions about body image, sense of self, peer relationships, leadership, and healthy decision making skills [31].

Mentors and mentees met one-on-one for one hour each week to engage in mutually agreed upon activities, such as tutoring and social outings. Dyads also participated in two-hour afterschool group mentoring sessions once a week with 8 other mentor-mentee pairs. Trained graduate and senior undergraduate students facilitated discussions about the SDT curriculum. Mentees completed self-report questionnaires in their school's computer lab in September-October (pre-test) and May-June (post-test).

Autonomy was measured using a 5-item assertiveness scale as it measures how much one feels they can assert themselves with other people (i.e., "How good are you at voicing your opinions and desires?"; "How good are you at getting someone to agree with your point of view?") [32]. Competence and Belonging were measured together using the Self-Esteem Questionnaire (SEQ) [33]. The SEQ has four sub-scales assessing family ("My family pays enough attention to me"); peer ("I am as popular with kids my own age as I want to be"); school ("I am good enough at math"); and global ("I am happy with the way I can do most things") self-esteem. The two sub-scales of global and school self-esteem were used to measure mentee self-perceptions of competence, while the peer and family sub-scales were used to measure mentee belongingness.

Results indicated no significant between- group differences on self-reported measures of autonomy, competence, or belonging. The researchers did find, however, that the experimental group did not experience the same amount of decline in global self-esteem over time compared to the control group, indicating that peer mentoring may buffer certain populations against this natural decline during adolescence [31].

The authors cite a few limitations of their study, the first of which is a small sample size, which limited their power to detect significant between group differences [31]. Secondly, the authors implemented indirect measures of autonomy, competence, and belonging, making it unknown whether or not significant differences would have been found if measures more closely aligned to the three basic needs were implemented [31]. Finally, the authors did not monitor mentor's fidelity of implementing the program and thus were not able to assess how well mentors adhered to the mentoring curriculum or what occurred in dyadic meetings [31]. This study also did not provide information as to how mentors were trained to satisfy the needs of their mentees, making it difficult to ascertain which training procedures may be 
beneficial.

\section{ReCIPROCAL BENEFITS OF SUPPORTING BASIC PSYCHOLOGICAL NEEDS}

The implementation of cross-age peer mentoring programs is increasing as they offer mentors the opportunities to learn leadership and relationship skills while simultaneously allowing mentees to form close relationships with older and more experienced peers [34]. The Helper Therapy Principle is often used to help explain the dual benefits of cross-age peer mentoring programs [35]. This principle suggests that by helping others, helpers benefit themselves during the process, and subsequently view themselves in a more favourable light. These reciprocal benefits arise when mentors are placed in a leadership role wherein the mentor is performing worthwhile actions and helping a younger student in need. Reissman (1965) stated that: “...some children develop not by being challenged by someone ahead of them, but by helping someone behind them" (p. 29) [35]. This principle plays a complementary role to Vygotsky's Zone of Proximal Development [36], arguing that learners are able to develop through both the guidance of an older and more experienced learner but also by acting as the older and more experienced learner. Research exploring the reciprocal benefits of supporting each basic psychological need will now be presented.

\section{A. Autonomy Support Reciprocity}

Since this study focuses on training high school peer mentors to become autonomy-supportive, an appropriate question is whether or not someone can learn how to become more autonomy-supportive? In the existing literature, some research has argued that autonomy support or non-support is a byproduct of personality and is therefore static and unalterable [29]. This thesis has been proven to be false, however, with research indicating that autonomy-support can be learned and developed, just like any other skill [29], [37].

Acknowledging that autonomy-supportive behaviours can be learned, the next logical question is whether or not high-school peer mentors can be trained to facilitate the satisfaction of their middle-school mentee's basic psychological needs? In the existing research on autonomy support, the majority of studies involve a more knowledgeable and experienced individual (i.e., teacher, manager, physician, and parent) providing support to a less experienced individual (i.e., child, student, patient, and employee). Although this discrepancy in experience is congruent with the traditional definition of a mentor, the age discrepancy of these studies raises some concerns regarding the generalizability to peer-with-peer mentoring programs. Thus, the existing research lacks investigation into how a more closely aligned relational partner, such as a peer mentor, may be able to influence their partner's need for autonomy.

Addressing this gap, researchers investigated the influence of autonomy support within peer friendships [38]. The authors of this study hypothesized that receiving autonomy support from a close friend would be associated with higher quality relationships and increased psychological well-being of the receiver [38]. It was also hypothesized that providing basic psychological need support to a friend would generate reciprocal benefits for the provider and promote their psychological well-being as well [38].

Participants included $(N=98)$ friendship-dyads from an undergraduate course in Psychology. When participants signed up for the study, their friends were recruited by asking them to bring a "close friend" to the next phase of the study. During the follow up meeting, participants were asked to complete several self-report questionnaires regarding the amounts of perceived autonomy support in their relationships and also the quality of their relationships. Friendship autonomy support was measured using an adapted version of the 10-item Health Care Climate Questionnaire [39]. Sample items include: "I feel that my friend provides me with choices and options", and "My friend tries to understand how I see things". Need satisfaction was measured using the Basic Psychological Need Satisfaction in Relationships Questionnaire (BNSIRQ) [40]. This 9-item questionnaire assesses the degree to which relational partners experience autonomy, competence, and belonging in their relationships (i.e., the three basic psychological needs). Sample items include: "When I am with my friend I feel free to be who I am" (i.e., Autonomy), "When I am with my friend I feel like a competent person" (i.e., Competence), and "When I am with my friend I feel loved and cared about" (i.e., Belonging). Self-report measures of emotional reliance, attachment security, and dyadic adjustment were also administered.

Results demonstrated that peers were able to provide one another with autonomy support, and that perceived autonomy support significantly predicted the subsequent basic psychological need satisfaction, emotional reliance, and attachment security between relational partners [38]. This is an important finding as it is the first to demonstrate the capacity of peers to promote the autonomy and subsequent need satisfaction of one another [38].

In an extension of their previous findings, the authors tested whether or not providing autonomy-support to a friend would influence the provider's basic psychological need satisfaction and psychological well-being. That is, would helping a peer satisfy their need for autonomy help promote the satisfaction of the provider's basic psychological needs? To examine this, participants completed an additional measure asking them to report how successful they felt they were in providing their friend with autonomy support. To measure the perceived autonomy support provided to friends, participants responded to the same 10-item measure used to assess perceived autonomy support received from others but with questions reworded. An example includes: "My friend believes that I provide them with choices and options". A measure of psychological well-being was also included in the second study (Centre for Epidemiological Studies Depression Scale (CES-D) [41].

The authors hypothesized that perceptions of high autonomy support provided to a friend would predict high perceptions of personal basic psychological need satisfaction, relationship quality, and psychological well-being [38]. Results indicated participants' perceptions of the degree to which they provided autonomy-support to a friend significantly predicted their basic psychological need satisfaction and psychological wellbeing, over-and-above the autonomy support they received from their friend [38]. In other words, perceptions of providing autonomy-support to 
others accounted for more variance in individual well-being than perceptions of receiving autonomy support from relational partners [38]. These findings lend support to the Helper Therapy Principle [35] and the potential for peer mentors to experience reciprocal benefits by helping to satisfy their mentees needs for autonomy, competence, and belonging.

In summary, these findings suggest that: (a) peers can successfully provide autonomy support to one another; and (b) helping others satisfy their need for autonomy can increase the psychological well-being of the provider at a greater level than simply receiving support from others. The data from this study were collected from peers in previously established friendships, however, and are thus only partially generalizable to mentoring programs. In mentoring programs, mentors and mentees are often unfamiliar with one another at the start of the program and develop a relationship as time progresses [1]. This being the case, an exploration of whether or not mentoring programs can facilitate the satisfaction of basic psychological needs amongst unfamiliar dyads is needed.

In a study using teacher-mentors and academically at-risk mentees, researchers examined the influence of mentee perceptions of autonomy and belonging on their academic engagement within a formal mentoring program [42]. The program is designed to match incoming college students with a teacher-mentor and, thus, dyads were unfamiliar with one another at the beginning of the program. Five teacher-mentors (aged 27-56) received one day of pre-match training with ongoing support via weekly meetings with the program coordinator. During training, mentors learned about the common stressors among college students and the types of support they could provide to alleviate their mentees' stress. Forty mentees ( $M=18.6$ years of age) participated in the program and met with their mentor once a week for a total of ten sessions. Self-report questionnaires were used to assess the perceived belonging and autonomy of mentees' after 5 months of mentoring. After data collection, mentees were divided into groups according to their self-reported ratings of basic psychological need satisfaction within their mentoring relationship (High vs. Low). Results found that mentored students in the high satisfaction condition, compared to the low satisfaction and comparison groups, scored significantly greater on all measures of academic engagement and achievement [42].

The results of this study demonstrate, perhaps only partially, the capacity of mentoring programs to promote the satisfaction of basic psychological needs. A significant limitation of this study involves the average age discrepancy between mentors and mentees, deeming it inappropriate to label this study as involving peer mentoring. The results of this study nevertheless illuminate the potential for once unfamiliar mentors to successfully promote the satisfaction of their mentee's needs for autonomy and belonging.

\section{A. Belonging Support Reciprocity}

Among most cross-age peer mentoring programs; a central tenet is to increase the sense of belonging and friendship among mentees towards their mentors. A secondary and often discussed corollary of this type of friendship and belonging support is the increased sense of belongingness among mentors.

To investigate the reciprocal benefits of mentoring, researchers implemented a quasi-experimental between-groups design to investigate how acting as a cross-age peer mentor influenced participant's self-esteem, school belongingness, and family and peer attachment compared to nonparticipating peers [8]. The average age of participating mentors $(N=46)$ was $(M=15.5)$ years of age and mentors participated in 8 hours of pre-match training alongside 2 hours of monthly supervision. In this study, mentors and mentees met weekly for 8 months on school-grounds and participated in a Saturday event once a month for 5 hours. Examples of Saturday events include visits to the zoo, picnics, and a carnival on school-grounds [8]. Mentor-mentee interactions were structured through a curriculum with dyads spending approximately half of their time engaged in structured activities and the other half in free play [8]. The curriculum was designed to foster close relationships between mentors and mentees and involves daily activities including an ice-breaker, a connectedness curriculum activity, a snack, and a final recreational activity (e.g., tag, basketball, art). Three self-report measures were implemented to assess participants' connectedness (Hemingway: Measure of Adolescent Connectedness) parent and peer attachment (Inventory of Parent and Peer Attachment), and self-esteem (Self-Esteem Questionnaire) [43]-[45].

Although no significant family-related outcomes were achieved, findings indicated that, compared to their nonparticipating peers, cross-age peer mentors reported gains in school belonging (i.e., with teachers and peers) and self-esteem (i.e., sports and academics). The results of this study [8] illuminate the benefits of acting as a cross-age peer mentor and the capacity of programs to promote mentors' sense of belongingness to school and peers.

\section{B. Competence Support Reciprocity}

As previously discussed in Section III, the provision of feedback and advice from mentors-to-mentees is a fundamental aspect of any mentoring relationship. Mentoring relationships exist in a vast array of contexts, however, and appropriate feedback styles may differ from one environment to another. In the present study, high-school mentors provided their mentees with feedback in a musical setting, a context that is often associated with the terms talent and ability [46]. Relevant literature on music-oriented feedback will now be reviewed in order to understand how feedback operates within this unique context.

Researchers examined the effects of verbal praise amongst $(N=87)$ fourth grade students participating in a rhythm-tapping test [47]. Prior to participation, each student was given a lesson on various strategies designed to help improve their rhythmic skills.

Each student was then initially exposed to an easy rhythm test followed by one of three feedback styles: (a) effort-focused (e.g., "You must have focused hard on the strategies before you played"); (b) ability-focused (e.g., "You must be talented in music"); or (c) no feedback. Following the administration of feedback, students were given the opportunity to attempt a learning goal (e.g., "Challenging rhythms that I can learn from even if I don't play them 
correctly") or a performance goal (e.g., "Rhythms I think I'm pretty good at so I can show how good I am in music"). Students were not exposed to these labels (performance vs. learning) but rather verbally expressed which goal they wanted to pursue on their own time after the test. Next, each student responded to questions on a 5-point Likert-type scale designed to assess their levels of task persistence (e.g., "How much would you like to take these rhythms home to practice them until they are perfect?") and task enjoyment (e.g., "How much did you enjoy playing the rhythms?"). Students were also asked to rate their task performance on a scale from 1 (poor) to 5 (perfect). Finally, a four coloured wheel was used to measure students' performance attributions. The four colours represented attributions of: effort (e.g., "I focused hard on the strategies"), talent (e.g., "Music is my thing"), time (e.g., "I had enough time"), and luck (e.g., "I was lucky"). This measure allowed students to rotate the wheel and place it on which attribution best represented their performance. In the second half of the experiment, students were exposed to a more difficult rhythm test and subsequently informed that they did not perform as well as they did on the first test. Participants then completed the same measures as the first test but with the attributions on the wheel being opposite (e.g., "Music is not my thing", "I didn't focus hard enough on the strategies"). The purpose of this second test was to expose children to a more challenging test after experiencing success in the first test to investigate how the various feedback groups responded to setbacks and hardship in a musical setting.

Results indicated that $90 \%$ of the students in the effort feedback group chose a learning goal after their performance compared to only $41 \%$ of the students in the ability feedback group [47]. Students in the no feedback group were divided equally into either category of goal selection. Mean scores of task persistence (i.e., willingness to practice rhythms at home) were also found to increase amongst the effort feedback group and decrease among the other two groups across the two rhythm tests. No significant between groups differences were found for either task enjoyment or performance ratings. Additionally, no significant between group differences were found regarding the four attributions of success on the colour wheel. Finally, although ratings of task enjoyment declined across all groups after the unsuccessful performance, students choosing to pursue learning goals reported significantly higher amounts of both task persistence and enjoyment compared to students who selected performance goals [47].

The results of this study are relevant to the present study as it is the first study to date to explore the influence of various feedback styles on young students in a musical setting. Results indicate that feedback should focus on the effort of the music student as it increases their willingness to engage in learning goals, the amount of effort they expend after setbacks, and the amount of enjoyment they experience during learning [47]. More importantly, feedback providers should make a concerted effort not to praise ability as this was shown to decrease student's effort, enjoyment, and willingness to expand their learning through challenging tasks [47].

As previously discussed, research has shown that acting as a cross-age peer mentor can promote reciprocal benefits in self-esteem and self-efficacy [8]. No studies to date, however, have examined how competence support in a musical setting by high-school peer mentors may reciprocally benefit their own sense of competence. In this study, high-school mentors were trained to provide effort-focused feedback to their mentees, addressing this gap in the literature and permitting statistical analyses to be conducted on the reciprocal benefits of competence support in cross-age peer mentoring.

\section{METHODS}

\section{A. Objective}

The objective of this study is to examine how acting as a high-school peer mentor influences the basic psychological needs (autonomy, belonging, and competence) of mentors.

Understanding whether or not high-school peer mentors benefit from helping a younger peer satisfy their basic psychological needs is an important endeavor as this type of reciprocity (i.e., reciprocal basic need satisfaction) has not been studied in the cross-age peer mentoring literature to date.

\section{B. Research Question}

The following research question is designed to investigate the aforementioned objective: (1) Once mentors are trained to support the basic psychological needs of their mentees and implement these strategies during mentoring sessions, will they experience the reciprocal satisfaction of their own autonomy, belonging, and competence?

\section{Participants}

Five mentor-mentee dyads were recruited to participate in this study from an after-school music program in in a low SES community in Western Canada. Mentees $(n=5)$ were elementary-aged students $(M=9.6$ years of age, $S D=1.81)$. All mentees were female and of Aboriginal and First Nations descent. Mentors $(n=5)$ were high-school aged students $(M$ $=15.8$ years of age, $S D=1.48$ ) drawn from grades 9 through 12. All mentors were female.

\section{Mentoring Context}

In the after-school music program, students learn to read and play classical music and sing in choirs. The program begins by providing students with a healthy meal full of fruits and vegetables to provide them with the necessary nutrients for learning. Students then attend various classes including Music Theory, Musicianship, Instrument Instruction (one of fourteen classical instruments), Vocal Instruction, and Collaborative Music (orchestra and ensembles). The program also offers Musical Therapy sessions to students experiencing physical and/or emotional trauma and a Youth Mentorship program designed to promote positive peer relationships and role modeling.

\section{E. Study Procedures}

This cross-age peer mentoring program was implemented for three months, beginning in March and concluding in May 2016. Dyadic mentoring sessions occurred once a week for one hour, consisting of twelve sessions in total. The amount $(\geq 10$ meetings) and frequency/consistency (1 interaction/week) of contact between mentoring dyads in this 
program adhere to 'best practices' identified in the existing cross-age peer mentoring literature [9].

\section{1) Mentor orientation and training}

Prior to being matched with their mentees, mentors participated in two 1-hour skill-building sessions.

In the first session, mentors were introduced to the concept of mentoring, identified healthy mentoring behaviours, and were made aware of the goals and expectations of the program, as well as the commitments required of them.

In the second session, mentors were introduced to the central ideas of SDT to promote a mentor approach that is oriented towards the satisfaction of their mentees basic psychological needs [10]. To begin, mentors collaboratively created an 'ABC Companion' where they defined autonomy, competence, and belonging together and also generated ways in which they could support these feelings in their mentees while making music together. This was accomplished by asking mentors to respond, in written form, to three questions asking them to define what "Autonomy is...Belonging is... and Competence is...". Once this was completed, mentors were asked to volunteer their answers to generate a discussion on the three basic psychological needs and their definitions. Next, mentors were asked to think about how they could promote these needs while interacting with their mentees by responding to three questions asking: "While making music together, how do you think you could make your mentee feel autonomous...competent...that they belonged... What could you say or do?". Mentors were then asked to volunteer their answers to generate a group discussion. During group conversations, a consensus was reached as to which definition mentors would use for each basic psychological need and the strategies in which they would attempt to promote them. Once complete, this 'ABC Companion' provided each mentor with a definition for each basic psychological need (i.e., "What Is It?") and strategies in which they can support this need (i.e., "Go-To-Statements" and "Go-To-Strategies"). Mentors then used their "ABC Companion' to practice providing basic psychological need support through various role playing situations. Completed 'ABC Companions' were provided to each mentor during mentoring sessions to help orient their efforts towards the promotion and satisfaction of their mentees basic psychological needs.

\section{2) Weekly mentoring structure}

During mentoring sessions, mentors and mentees made music together under the direction of a musician-teacher employed by the after-school music program. During mentoring sessions, mentors taught their mentees how to play various pieces of music that they each composed on their respective instruments ( 2 violins, 1 guitar, and 1 cello). At the conclusion of the cross-age peer mentoring program, mentoring dyads synchronized their respective parts into a song and had it professionally recorded. At the end of each mentoring session, mentors were asked to complete a 'Weekly Learning Log' designed to capture the methods in which they attempted to promote the basic psychological needs of their mentee.

\section{3) Mentor support meetings}

To help support the on-going learning and practice of mentors throughout this 3-month program, mentors attended two 'Mentor Support Meetings' where they completed learning templates and discussed their mentoring practice together. Learning templates asked mentors to identify "What They Tried" (e.g., how they attempted to support their mentees basic psychological needs), "How It Went" (e.g., what strategies worked well and which ones did not), "What Did You Learn" (e.g., about being a mentor, about your mentee), and "What Will You Try" (e.g., how do you plan to support your mentee in the upcoming weeks?).

\section{4) Assessment of mentor basic psychological need satisfaction}

The level of basic psychological need satisfaction for each mentor was assessed after 4 weeks (Time 1) and 8 weeks (Time 2) of mentoring. A baseline measure of basic psychological need satisfaction was not appropriate as mentors had not yet met their mentees and therefore, could not have had experienced any satisfaction of their needs.

\section{B. Measures}

The Basic Need Satisfaction in Relationships Questionnaire (BNSIRQ) was used to assess the basic psychological need satisfaction of high-school mentors in their mentoring relationships [48]. The BNSIRQ is a 9-item scale, assessing each basic psychological need with 3 items. Each item is responded to on a 7- point scale ranging from (1 $=$ not at all true $)$ to $(7=$ very true $)$. Sample items include: "When I am with my mentee, I have a say in what happens, and can voice my opinion" (autonomy); "When I am with my mentee, I feel loved and cared about" (belonging); and "When I am with my mentee, I feel very capable and effective" (competence). Average scores for each basic psychological need are created by generating the mean of each respective sub-scale (some items are reverse-coded). Higher scores and subsequent means are indicative of higher levels of basic need satisfaction within mentor-mentee relationships. Previous research using the BNSIRQ found that overall basic psychological need satisfaction in friendships was positively correlated with well-being and happiness [22], [48], [49]. The reliability of the total scale has also been demonstrated in several studies (alphas ranging from .65 to .94), [48], [50], alongside the internal consistencies of autonomy (.74), belonging (.80), and competence (.76) [51].

\section{Statistical Analysis}

Version 22.0 of the Statistical Package for the Social Sciences (SPSS) software was used for data analysis. All quantitative variables were checked for Normality using the Shapiro-Wilks test. A paired-samples t-test was conducted to compare the levels of mentor basic psychological need satisfaction at 4-weeks (Time 1) and 8-weeks (Time 2).

\section{Results}

The test for normality, examined using the Shapiro-Wilk's test, indicated the data were statistically normal for Autonomy $\mathrm{W}(5)=0.817, p=.111$; Belonging $\mathrm{W}(5)=0.867$, $p=0.256$; and Competence $\mathrm{W}(5)=0.870, p=0.265$ scores between Time 1 and Time 2. There was a non-significant difference between the levels of mentor reported autonomy satisfaction at week $4(M=6.54, S D=0.55)$ and week $8(M=$ $6.74, S D=0.43$ ) of cross-age peer mentoring; $t(4)=-2.39, p$ 
$=0.075$. Similarly, there was a non-significant difference between the levels of belonging satisfaction that mentors reported at week $4(M=5.74, S D=0.66)$ and week $8(M=$ $6.46, S D=0.40)$ of cross-age peer mentoring; $t(4)=-2.19, p$ $=0.094$. There was, however, a significant difference in the levels of competence satisfaction that mentors reported at week $4(M=6.14, S D=0.43)$ and at week $8(M=6.82, S D=$ $0.16)$ of cross-age peer mentoring; $t(4)=-4.65, p=0.010$, $<.05$.

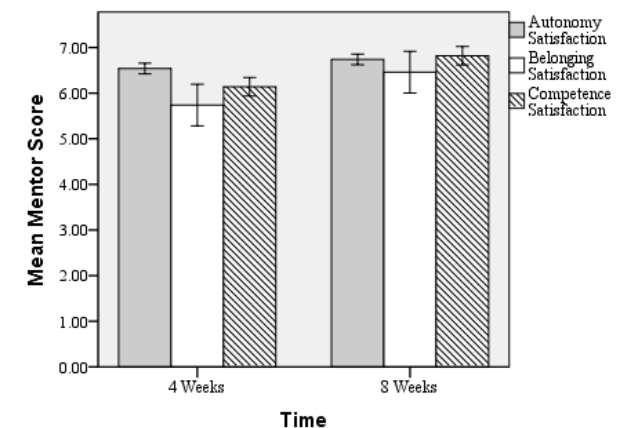

Fig. 1. Mentor basic psychological need satisfaction.

\section{DISCUSSION}

Cross-age peer mentoring is an attractive developmental intervention and/or program as it produces benefits for both mentees and mentors [2], [4]. This paper reviewed the extant literature on the reciprocal benefits of mentoring and explored the results of a mentoring program situated in a musical context for 'at-risk' youth. This study is unique as it is the first to train high-school aged mentors to support the basic psychological needs (i.e., autonomy, competence and belonging) of their middle-school aged mentees. Investigating the potential of this training approach, and its ability to promote reciprocal benefits for mentors is an important extension of the literature as past authors have recommended studying the mentoring process using new theoretical frameworks [9].

The results of this study demonstrate that reciprocal benefits can be achieved for mentors when they orient their efforts towards supporting the autonomy, competence, and belonging of their mentees during dyadic mentoring sessions. Mentors demonstrated increased satisfaction of each basic psychological need from Time 1 (4-weeks of mentoring) to Time 2 (8-weeks of mentoring), with only competence satisfaction reaching statistical significance. The results of this study are consistent with [8] and [52].

\section{CONCLUSION}

This study illuminates the potential for cross-age peer mentoring programs to promote reciprocal benefits for mentors when they participate in skill-building sessions designed to increase their understanding of SDT and are equipped with strategies to promote and satisfy their mentees needs for autonomy, competence and belonging.

The theoretical implications of this research involve contributing to the ongoing discussion of both how and why the cross-age peer mentoring process produces beneficial outcomes for participating mentors [9]. Specifically, this study found that the mentoring process produces beneficial outcomes for mentors by supporting their basic psychological needs (how) through the act of helping a younger and less experienced peer satisfy their needs for autonomy, belonging and competence (why). These reciprocal benefits are explained by The Helper Therapy Principle [35] and are consistent with existing literature on Positive Psychology and the benefits of kindness (i.e., the "kindness-happiness loop") [53]. In summary, it seems as though SDT plays a complementary role to the existing theoretical frameworks in the cross-age peer mentoring literature and adds value to the discussion of the developmental process of mentoring.

In a practical sense, this research offers knowledge on the benefits of having older and more experienced students mentor and teach their younger and less experienced peers. Classroom teachers, after-school personnel, and little league coaches may benefit from this research as it provides guidelines and empirical support for the implementation of a mentoring program for their children/youth. Teachers or coaches looking to increase the sense of competence amongst their elder students/players may draw upon these findings while attempting to develop an intervention strategy.

\section{REFERENCES}

[1] M. J. Karcher, "The effects of school-based developmental mentoring and mentors'attendance on mentees' self-esteem, behavior, and connectedness," Psychology in the Schools, vol. 42, pp. 65-77, 2005.

[2] M. J. Karcher, "The study of mentoring in the learning environment (SMILE): A randomized evaluation of the effectiveness of school-based mentoring," Prevention Science, no. 9, p. 2, 2008.

[3] J. E. Rhodes, "A model of youth mentoring," in D. L. DuBois and M. J. Karcher (Eds.), Handbook of Youth Mentoring, Thousand Oaks, CA: Sage, pp. 30-43, 2005.

[4] D. L. D. Bois and M. A. Karcher, Handbook of Youth Mentoring, Thousand Oaks, CA: Sage, 2005.

[5] J. E. Rhodes, "Older and wiser: Mentoring relationships in childhood and adolescence," The Journal of Primary Intervention, vol. 14, no. 3, pp. 187-196, 1994

[6] J. Bowlby, Attachment and Loss: Volume 1. Attachment, New York: Basic Books, 1969.

[7] M. Rutter, "Implications of resilience concepts for scientific understanding," Annals of the New York Academy of Sciences, pp. 1-12, 2006.

[8] M. J. Karcher, "Increases in academic connectedness and self-esteem among high school students who serve as cross-age peer mentors," Professional School Counseling, vol. 12, no. 4, pp. 292-299, 2009.

[9] N. L. Deutsch and R. Spencer, "Capturing the magic: Assessing the quality of youth mentoring relationships," New Directions for Youth Development, vol. 121, 2009

[10] R. M. Ryan and E. L. Deci, "Self-determination theory and the facilitation of intrinsic-motivation, social development, and well-being," American Psychologist, vol. 55, pp. 68-78, 2000.

[11] R. F. Baumeister and M.R. Leary, "The need to belong: Desire for inter- personal attachments as a fundamental human motivation," Psychological Bulletin, vol. 117, no. 3, pp. 497-529, 1995.

[12] E. L. Deci, G. Betley, J. Kahle, L. Abrams, and J. Porac, "When trying to win: Competition and intrinsic motivation," Personality and Social Psychology Bulletin, vol. 7, pp. 79-83, 1981.

[13] R. M. Ryan, C. Chandler, J. P. Connell, and E. L. Deci, "Internalization and motivation: preliminary research and theoretical speculations," Paper Presented at the Annual Meeting of the Society for Research in Child Development, Detroit, 1983

[14] E. L. Deci and R. M. Ryan, Intrinsic Motivation and Self-Determination in Human Behavior, New York, NY: Plenum, 1985 .

[15] E. L. Deci and W. F. Cascio, "Changes in intrinsic motivation as a function of negative feedback and threats," presented at the Eastern Psychological Association Convention, April 1972.

[16] E. L. Deci, Intrinsic Motivation, New York: Plenum, 1975.

[17] W. S. Grolnick, E. L. Deci, and R. M. Ryan, (1997), "Internalization within the family: The self-determination theory perspective," In J. E. Grusec \& L. Kuczynski (Eds.) Parenting and Children's 
Internalization of Values: A Handbook of Contemporary Theory, pp. 135-161, 1997.

[18] R. M. Ryan, K. M. Sheldon, T. Kasser, and E. L. Deci, "All goals are not created equal: An organismic perspective on the nature of goals and their regulation," The Psychology of Action: Linking Cognition and Motivation to Behavior, New York: Guilford, pp. 7-26, 1996.

[19] E. L. Deci, J. G. L. Guardia, C. A. Moller, M. J. Scheiner, and R. M Ryan, "On the benefits of giving as well as receiving autonomy support: Mutuality in close friendships," The Society for Personality and Social Psychology, vol. 32, no. 3.

[20] J. Reeve, "Autonomy, volitional motivation, and wellness," Motivation and Emotion, vol. 30, pp. 257-258, 2006.

[21] P. P. Baard, E. L. Deci, R. M. Ryan, "Intrinsic need satisfaction: A motivational basis of performance and wellbeing in two work settings," Journal of Applied Social Psychology, vol. 34, pp. 2045-2068, 2004.

[22] E. L. Deci, R. M. Ryan, and G. C. Williams, "Need satisfaction and the self-regulation of learning," Learning and Individual Differences, vol. 8, pp. 165-183, 1996.

[23] R. M. Ryan and E. L. Deci, "Self-determination theory and the facilitation of intrinsic motivation, social development, and well-being," American Psychologist, vol. 55, pp. 68-78, 2000.

[24] R. E. White, "Motivation reconsidered: The concept of competence," Psychological Review, vol. 66, no. 5, 1959.

[25] A. Bandura, Self-efficacy: The Exercise of Control, New York: Freeman, 1997.

[26] M. Halusic and J. Reeve, "Instructional strategies to nurture students' inner motivational resources," University of Iowa, 2009.

[27] J. Reeve, "Autonomy, volitional motivation, and wellness," Motivation and Emotion, vol. 30, pp. 257-258, 2006.

[28] Dweck, C. S. (2000), Self-theories: Their role in Motivation, Personality and Development, Taylor \& Francis: Philadelphia, PA

[29] D. Goleman, Social Intelligence: The New Science of Human Relationships, New York: Bantam Books, 2006

[30] F. Simoes and M. Alarcao, "Promoting well-being in school-based mentoring through basic psychological needs support: Does it really count?" Journal of Happiness Studies, vol. 15, pp. 407-424, 2014

[31] A. K. Henneberger, N. L. Deutsch, E. C. Lawrence, and A. Sovik-Johnston, "The young women leaders program: A mentoring program targeted toward adolescent girls," School Mental Health, vol. 5, no. 3, pp. 132-143, 2013

[32] D. Buhrmester, W. Furman, M. T. Wittenberg, and H. T. Reis, "Five domains of interpersonal competence in peer relationships," Journal of Personality and Social Psychology, vol. 55, no. 6, pp. 991, 1988.

[33] D. L. DuBois, R. D. Felner, S. Brand, R. S. Phillips, and A. M. Lease, "Early adolescent self-esteem: A developmental ecological framework and assessment strategy," Journal of Research on Adolescence, vol. 6, no. 4, pp. 543-579, 1996.

[34] M. J. Karcher, "Cross-age peer mentoring," Youth Mentoring. Research in Action, vol. 1, no. 7, p. 3017, 2007.

[35] F. Riessman, "The 'helper' therapy principle," Social Work, vol. 10, no. 2, pp. 27-32, 1965 .

[36] L. S. Vygotsky, Mind in Society: The Development of Higher Psychological Processes, Cambridge, MA: Harvard University Press, 1978.

[37] J. Reeve, H. Jang, D. Carrell, J. Barch, and S. Jeon, “"Enhancing high school students' engagement by increasing their teachers' autonomy support," Motivation and Emotion, vol. 28, pp. 147-169, 2004

[38] E. L. Deci, J. G. La Guardia, A. C. Moller, M. J. Scheiner, and R. M. Ryan, "On the benefits of giving as well as receiving autonomy support: Mutuality in close friendships," Personality and Social Psychology Bulletin, vol. 32, pp. 313-327, 2006.

[39] G. C. Williams, E. M. Cox, R. Kouides, and E. L. Deci, "Presenting the facts about smoking to adolescents: The effects of an autonomy supportive style," Archives of Pediatrics and Adolescent Medicine, vol. 153, pp. 959-964, 1999.
[40] J. G. L. Guardia, R. M. Ryan, C. E Couchman, and E. L. Deci, "Within-person variation in security of attachment: A self-determination theory perspective on attachment, need fulfillment, and well-being," Journal of Personality and Social Psychology, vol. 79, pp. 367-384, 2000

[41] L. S. Radloff, "The CES-D Scale: A self-report depression scale for research in the general population," Applied Psychological Measurement, vol. 1, no. 3, 1977.

[42] S. Larose, G. Tarabulsy, and D. Cyrenne, "Perceived autonomy and relatedness as moderating the impact of teacher-student mentoring relationships on student academic adjustment," The Journal of Primary Prevention, vol. 26, pp. 111-128, 2005.

[43] M. J. Karcher and J. Lindwall, "Social interest, connectedness, and challenging experiences: What makes high school mentors persist?" Journal of Individual Psychology, vol. 59, pp. 293-315, 2003.

[44] G. C. Armsden and M. T. Greenberg, "The Inventory of parent and peer attachment (IPPA): Relationship to well-being in adolescence," Journal of Youth Adolescence, vol. 16, pp. 427-454, 1987.

[45] D. L. DuBois, R. D. Felner, S. Brand, R. S. Phillips, and A. M. Lease, "Early adolescent self-esteem: A developmental ecological framework and assessment strategy," Journal of Research on Adolescence, vol. 6 , no. 4, pp. 543-579, 1996

[46] J. R. Austin and W. P. Vispoel, "How American adolescents interpret success and failure in music: Relationships among attributional beliefs, self-concept and achievement," Psychology of Music, vol. 26, pp 26-45,1998

[47] L. K. Droe, "Effect of verbal praise on achievement goal orientation, motivation, and performance attribution," Journal of Music Teacher Education, vol. 23, no. 1, pp. 63-78, 2012.

[48] J. G. L. Guardia, R. M. Ryan, C. E. Couchman, and E. L. Deci, "Within-person variation in security of attachment: A self-determination theory perspective on attachment, need fulfillment, and well-being," Journal of Personality and Social Psychology, vol. 79, pp. 367-384, 2000

[49] A. O"zen, N. Su"mer, and M. Demir, "Predicting friendship quality with rejection sensitivity and attachment security," Journal of Social and Personal Relationships, vol. 28, pp. 16-181, 2011.

[50] M. Demir and M. O. Zdemir, "Friendship, need satisfaction and happiness," Journal of Happiness Studies, vol. 11, pp. 243-259, 2010

[51] D. H. Zand, N. Thomson, R. Cervantes, R. Espiritu, D. Klagholz, L. LaBlanc, and A. Taylor, "The mentor-youth alliance: The role of mentoring relationships in promoting youth competence," Journal of Adolescence, vol. 32, pp. 1-17, 2009.

[52] L. B. Aknin, E. W. Dunn, and M. I. Norton, "Happiness runs in circular motion: Evidence for a positive feedback loop between prosocial spending and happiness," Journal of Happiness Studies, vol. 13 , no. 2 , pp. $347-355,2011$.

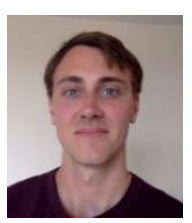

Benjamin Dantzer was born in London, Ontario Canada, in 1992. He received his bachelor of arts (B.A) in psychology from the University of Western Ontario, Canada in 2014. He is currently working towards his master of arts (M.A) degree in human development, learning, and culture at the University of British Columbia (UBC), Vancouver, Canada. Ben is a research coordinator at the Centre for Brain Health, UBC Hospital, Vancouver, Canada. His research focuses on improving the well-being and livelihood of 'at risk' children and adolescents, covering a range of topics including social relationships, physical activity, and self-regulation. Mr. Dantzer was awarded the Joseph-Armand Bombardier Canadian Graduate Studen Scholarship to pursue his masters research exploring how the self-determination and well-being can be supported in youth living in the lowest SES community in Canada. 